\title{
ANALISIS PENURUNAN BADAN JALAN KM 605+400 RUAS JALAN SUBULUSSALAM-LIPAT KAJANG DIPERKUAT PONDASI CAKAR AYAM MODIFIKASI
}

\author{
Ali Munir ${ }^{1}$, Munirwansyah ${ }^{2}$, Sofyan M. Saleh ${ }^{3}$ \\ ${ }^{1)}$ Magister Teknik Sipil, Fakultas Teknik, Universitas Syiah Kuala, Banda Aceh \\ ${ }^{2), 3)}$ Jurusan Teknik Sipil, Fakultas Teknik, Universitas Syiah Kuala, Banda Aceh \\ e-mail :munirali34@yahoo.com
}

DOI: http://dx.doi.org/10.29103/tj.v10i2.317

(Received: June 2020 / Revised: August 2020 / Accepted: August 2020)

\begin{abstract}
Abstrak
Ruas Jalan Subulussalam-Lipat Kajang merupakan salah satu jalan Nasional Lintas Barat-Selatan Provinsi Aceh menghubungkan Kota Subulussalam dengan Kabupaten Aceh Singkil dan menuju Batas Provinsi Sumatera Utara mengalami penurunan pada badan jalan pada $\mathrm{Km} 605+400$. Penurunan disebabkan oleh aliran air dan rendahnya daya dukung tanah serta berubahnya sifat tanah dasar menjadi lunak atau berkurangnya volume akibat proses penyusutan. Oleh sebab itu, diperlukan kajian penurunan kontruksi badan jalan dan upaya penanggulangannya dengan menggunakan pondasi Cakar Ayam Modifikasi (CAM). Kajian ini bertujuan untuk menganalisis penurunan kontruksi badan jalan dengan mendapatkan angka penurunan dalam batasbatas toleransi. Analisis yang dilakukan untuk mendapatkan penurunan yaitu dengan menggunakan program Plaxis 2D. Ruang lingkup penelitian yang akan dilakukan meliputi menganalisis penurunan sebelum dan setelah dilakukan penanganan menggunakan Pondasi Cakar Ayam Modifikasi (CAM) dengan Lebar $80 \mathrm{~cm}$, Tinggi $120 \mathrm{~cm}$ dan jarak antar pondasi $250 \mathrm{~cm}$. Hasil analisis penurunan pada kondisi eksisting dengan menggunakan program Plaxis 2D, diperoleh angka penurunan yaitu lebih besar dari $2,5 \mathrm{~cm}$ (batas-batas toleransi) dengan jangka waktu di atas 11,36 tahun dalam kondisi badan jalan tidak aman, sedangkan hasil analisis penurunan setelah dilakukan penanganan dengan Pondasi Cakar Ayam Modifikasi (CAM) menggunakan program Plaxis 2D, diperoleh angka penurunan yaitu lebih kecil dari 2,5 cm dengan jangka waktu dibawah Tv 3,60 tahun dalam kondisi badan jalan aman.
\end{abstract}

Kata kunci: Penurunan, Pondasi CAM, Plaxis 2D

\begin{abstract}
Roads Subulussalam - Lipat Kajang is one of the national road along the west - south province of Aceh connect Subulussalam City with Aceh Singkil Regency and heading to the North Sumatra Province Border has decreased on the road body at Km $605+$ 400. The decline is caused by water flow and low carrying capacity soil as well as changing the nature of subgrade to soft or reduced volume due to the shrinkage process. Therefore, it is necessary to review the reduction in road construction and efforts to overcome it by using the foundation of CAM. This study aimed to analyze the decrease in construction of the road to get the numbers decrease in the tolerance limits. The analysis is conducted to get the decline using the Plaxis 2D program. The scope of the research will include analyzing the decrease before and after handling using Foundation of CAM with Width $80 \mathrm{~cm}$, Height $120 \mathrm{~cm}$ and distance between foundations $250 \mathrm{~cm}$. The results of the analysis of the decline in existing conditions by using the Plaxis 2D program, obtained a decrease in numbers that is greater than 2.5
\end{abstract}

Analisis Penurunan Badan Jalan Km 605+400 Ruas Jalan Subulussalam-Lipat Kajang Diperkuat Pondasi Cakar Ayam Modifikasi - Ali Muni, Munirwansya, Sofyan M. Saleh 
$\mathrm{cm}$ (tolerance limits) with a period of over 11,36 years in unsafe road body conditions, while the results of the analysis of the decline after handling with the foundation of CAM using the Plaxis 2D program, obtained a reduction rate that is smaller than 2.5 $\mathrm{cm}$ with a period under TV 3,60 years in safe road body conditions.

Keywords: Sattlement, Foundation of CAM, Plaxis $2 D$

\section{Latar Belakang}

Ruas Jalan Subulussalam-Lipat Kajang Km 605+400 merupakan salah satu jalan Nasional Lintas Barat-Selatan Provinsi Aceh yang menghubungkan Kota Subulusslam dengan Kabupaten Aceh Singkil dan menuju batas provinsi Sumatera Utara. Selain itu, ruas jalan ini juga merupakan salah satu akses dari arah Subulussalan menuju ke Kabupaten Aceh Singkil dan sebaliknya. Seiring dengan bertambahnya volume lalu lintas pada ruas jalan tersebut dapat menyebabkan terjadi penurunan (settlement) pada kontruksi badan jalan. Peristiwa terjadinya penurunan pada badan jalan dapat mengakibatkan akses lalu lintas menjadi terhambat dari arah Subulussalam menuju Lipat Kajang dan sebaliknya. Penurunan (settlement) pada ruas jalan Subulussalam-Lipat Kajang Km 605+400 dapat dilihat pada Gambar 1.

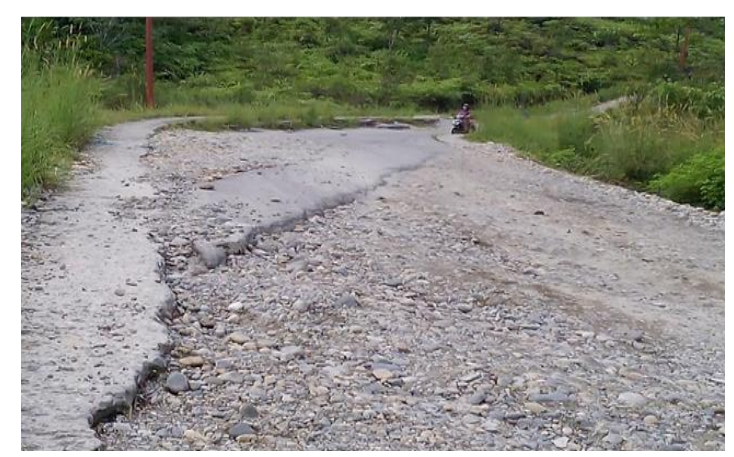

Gambar 1 Penurunan (Settlement) pada ruas jalan Subulussalam - Lipat Kajang $\mathrm{Km} 605+400$

Penurunan (settlement) pada ruas jalan Subulussalam-Lipat Kajang Km 605+400 dapat disebabkan oleh aliran air (freatic line) dan rendahnya daya dukung tanah serta berubahnya sifat tanah dasar menjadi lunak atau terjadinya pengurangan pada volume akibat proses penyusutan. Aliran air (freatic line) adalah aliran air tanah yang lokasinya berada pada permukaan tanah dangkal. Adapun tujuan dari penelitian ini adalah untuk menganalisa penurunan (settlement) kontruksi badan jalan pada kondisi eksisting setelah menggunakan pondasi Cakar Ayam Modifikasi (CAM) menggunakan program plaxis 2D.

Pondasi sistem cakar ayam ditemukan oleh Prof. Dr. Ir. Sedijatmo pada tahun 1961 (Hardiyatmo, 2010). Secara umum perkerasan cakar ayam terdiri dari pelat tipis beton bertulang tebal $10-17 \mathrm{~cm}$ yang diperkaku dengan pipa-pipa beton (cakar) berdiameter $120 \mathrm{~cm}$, tebal $8 \mathrm{~cm}$, dan panjang pipa $150-200 \mathrm{~cm}$, yang tertanam pada lapisan subgrade, dengan jarak pipa-pipa berkisar 2,0-2,5 m, di mana pada bawah pelat beton, terdapat lapisan lean concrete setebal $\pm 10 \mathrm{~cm}$ (terbuat dari beton mutu rendah) dan lapisan sirtu setebal $\pm 30 \mathrm{~cm}$ yang berfungsi, terutama sebagai perkerasan sementara selama masa pelaksanaan dan agar permukaan subgrade dapat rata sehingga pelat beton cakar ayam dapat 
dibuat di atasnya. Pipa-pipa beton tersebut disebut cakar. Kedalaman/tinggi pelat beton untuk penghalang kelembaban (koperan) ini antara 0,5-1,20 m (Hardiyatmo, 2017), bergantung pada potensi pengembangan dan kedalaman zona aktif di lokasi rencana jalan.

Penelitian ini bertujuan untuk menganalisis penurunan kontruksi badan jalan dengan mendapatkan angka penurunan dalam batas-batas toleransi. Analisis penurunan dengan menggunakan program Plaxis 2D.

\section{Metode Penelitian}

Metode penelitian merupakan langkah-langkah yang dilakukan secara sistematis dengan kerangka acuan yang jelas dalam menyelesaikan permasalahan. Dalam subbab ini akan dijelaskan mengenai metodologi penelitian untuk menentukan hasil yang ingin dicapai sesuai dengan tujuan yang ada. Mulai dari lokasi penelitian, pengumpulan data, pengolahan data, kemudian dianalisis secara manual dan program Plaxis 2D (Broere, 2004).

\subsection{Lokasi Penelitian}

Lokasi penelitian ini terletak di Ruas Jalan Subulussalam-Lipat Kajang tepatnya pada Km 605+400 di Kabupaten Gayo Lues Provinsi Aceh.

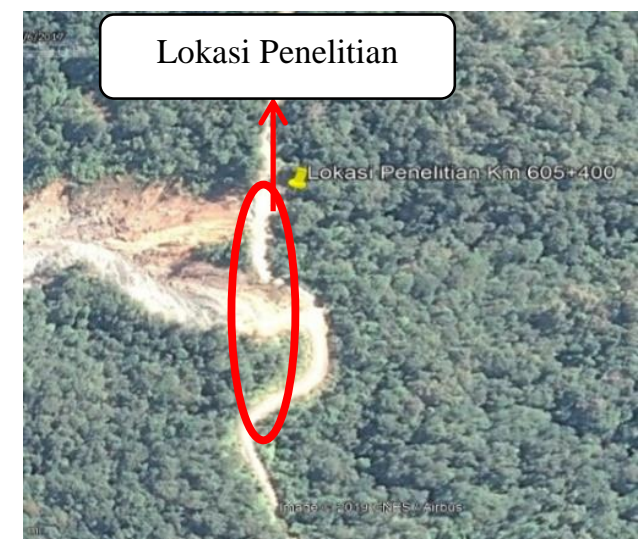

Gambar 2 Kondisi penurunan badan jalan pada lokasi penelitian

\subsection{Geometri Lereng}

Geometri lereng diperlukan sebagai data lereng untuk membuat penampang melintang lereng di dalam program Plaxis 2D agar penurunan pada badan jalan yang akan dianalisa sesuai dengan di lapangan. Ruang lingkup tinjauan analisis konsolidasi badan jalan pada Ruas Jalan Subulussalam-Lipat Kajang Km 605+400 meliputi penentuan geometri lereng, menentukan parameter tanah yang akan digunakan dan melakukan evaluasi penurunan badan jalan.

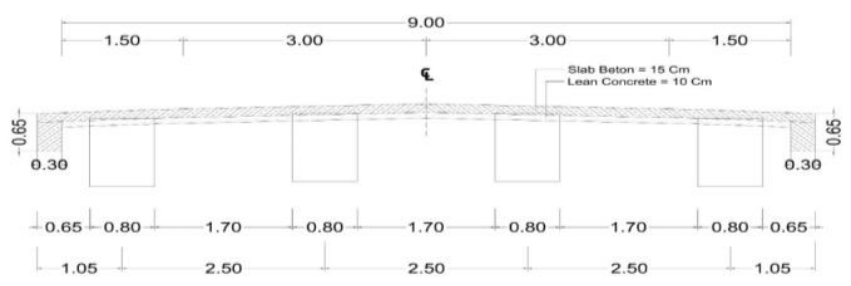

Gambar 3 Dimensi pondasi cakar ayam modifikasi 
Penelitian ini akan dilakukan pada lereng kondisi eksisting dan kondisi setelah diberi perkuatan dengan Pondasi Cakar Ayam Modifikasi (CAM). Untuk dimensi Pondasi Cakar Ayam Modifikasi dapat dilihat pada Gambar 3.

\subsection{Parameter Tanah}

Parameter tanah ini merupakan data yang digunakan untuk memperoleh hasil perhitungan analisis konsolidasi pada badan jalan. Data yang digunakan untuk analisis konsolidasi pada badan jalan dengan menggunakan program Plaxis 2D (Wirhadi et al., 2018); (Bowles, 1993) adalah berat volume tanah $(\gamma)$, kohesi (c), dan sudut geser $(\phi)$ yang diperoleh dari hasil pengujian sampel tanah pada Ruas Jalan Subulussalam-Lipat Kajang Km 605+400. Sedangkan untuk Poisson ratio $(\mathrm{v})$, modulus Young $\left(\mathrm{E}_{\mathrm{ref}}\right)$ dan koefisien permeabilitas tanah $(\mathrm{k})$ diperoleh dari hasil interpretasi sesuai jenis tanah yang didiskripsikan setelah pengujian.

Untuk membuat material Pondasi Cakar Ayam Modifikasi (CAM), dapat mengulangi langkah seperti membuat properti material tanah, hanya saja nilai untuk parameternya yang berbeda. Adapun parameter untuk Pondasi Cakar Ayam Modifikasi (CAM) dapat dilihat pada Tabel 1.

Tabel 1 Parameter input pondasi cakar ayam modifikasi (CAM)

\begin{tabular}{lccc}
\hline \multicolumn{1}{c}{ Properties } & Simbol & Nilai & Unit \\
\hline Model material & Model & Elastic Linier & - \\
\hline Material behavior & Type & Non Porous & - \\
\hline Berat volume beton & $\gamma$ & 25 & $\mathrm{kN} / \mathrm{m}^{3}$ \\
\hline Modulus elastisitas & $\mathrm{E}_{\mathrm{ref}}$ & $2,574 \times 10^{7}$ & $\mathrm{kN} / \mathrm{m}^{2}$ \\
\hline Poisson's ratio & $v$ & 0,15 & - \\
\hline
\end{tabular}

Tabel 2 Parameter data yang digunakan pada program Plaxis 2D

\begin{tabular}{lcccc}
\hline \multirow{2}{*}{ Parameter Tanah } & \multicolumn{3}{c}{ Km 605+400 } & \multirow{2}{*}{ Satuan } \\
\cline { 2 - 5 } & Lapisan 1 & Lapisan 2 & Lapisan 3 & \\
\hline Material model & MC & MC & MC & - \\
\hline Type of behaviour & Drained & Drained & Undrained & - \\
\hline Dry soil weight $\left(\square_{\mathrm{dry}}\right)$ & 13,100 & 18,906 & 15,156 & $\mathrm{kN} / \mathrm{m}^{3}$ \\
\hline Wet soil weight $\left(\square_{\text {wet }}\right.$ & 16,088 & 21,778 & 19,031 & $\mathrm{kN} / \mathrm{m}^{3}$ \\
\hline Horizontal permeability $\left(\mathrm{k}_{\mathrm{x}}\right)$ & 0,001 & 0,0001 & 0,0000001 & $\mathrm{~m} / \mathrm{day}$ \\
\hline Vertical permeability $\left(\mathrm{k}_{\mathrm{y}}\right)$ & 0,001 & 0,0001 & 0,0000001 & $\mathrm{~m} / \mathrm{day}^{2}$ \\
\hline Young's modulus $\left(\mathrm{E}_{\mathrm{ref}}\right)$ & 9810 & 24525 & 14715 & $\mathrm{kN} / \mathrm{m}^{2}$ \\
\hline Poisson's ratio $(\mathrm{v})$ & 0,350 & 0,300 & 0,300 & - \\
\hline Cohession $(\mathrm{c})$ & 0,000 & 2,453 & 8,142 & $\mathrm{kN} / \mathrm{m}^{2}$ \\
\hline Friction angle $(\mathrm{f})$ & 33,940 & 31,840 & 21,900 & $\circ$ \\
\hline Dilatancy angle $(\Psi)$ & 3,940 & 1,840 & 0,000 & $\circ$ \\
\hline
\end{tabular}

\subsection{Beban Lalu Lintas}

Besarnya pembebanan untuk analisis stabilitas lereng dapat mengacu pada panduan Geoteknik 4 No Pt T-10-2002-B (DPU, 2002b) (Umum, 2009) seperti diperlihatkan pada Tabel 3.

Analisa konsolidasi dengan menggunakan software Plaxis akibat pengaruh beban lalulintas yang bekerja pada ruas jalan Subulussalam-Lipat Kajang merupakan jalan nasional yang termasuk kategori jalan kelas I, dengan fungsi jalan arteri dan beban lalu lintas sebesar $15 \mathrm{kN} / \mathrm{m}^{2}$. 
Tabel 3 Beban lalu lintas untuk analisis stabilitas lereng

\begin{tabular}{|c|c|c|c|}
\hline Fungsi & Sistem Jaringan & $\begin{array}{c}\text { Lalu Lintas Harian Rata- } \\
\text { Rata (LHR) } \\
\end{array}$ & $\begin{array}{c}\text { Beban Lalu Lintas } \\
\left(\mathrm{kN} / \mathrm{m}^{2}\right) \\
\end{array}$ \\
\hline \multirow{3}{*}{ Primer } & Arteri & Semua & 15 \\
\hline & \multirow{2}{*}{ Kolektor } & $>10000$ & 15 \\
\hline & & $<10000$ & 12 \\
\hline \multirow{6}{*}{ Sekunder } & \multirow{2}{*}{ Arteri } & $>20000$ & 15 \\
\hline & & $<20000$ & 12 \\
\hline & \multirow{2}{*}{ Kolektor } & $>6000$ & 12 \\
\hline & & $<6000$ & 10 \\
\hline & \multirow{2}{*}{ Lokal } & $>500$ & 10 \\
\hline & & $<500$ & 10 \\
\hline
\end{tabular}

Sumber Panduan Geoteknik 4 No Pt T-10-2002-B (DPU, 2002b)

Berdasarkan teori Terzaghi (Bowles, 1986); (Punmia, 1981), tentang konsolidasi satu dimensi, penurunan konsolidasi untuk konsolidasi normal dapat dihitung dengan persamaan berikut:

$$
S c=\frac{C c}{1+e_{0}} H \log \left(\frac{\sigma^{\prime} z f}{\sigma^{!} z_{0}}\right)
$$

Keterangan:

$S_{c}=$ Penurunan Konsolidasi (m);

$C_{c} \quad=$ Nilai Compression Index;

$e_{0} \quad=$ Void Ratio awal;

$H \quad=$ Tinggi tanah terkonsolidasi (m);

$\sigma_{z 0}=$ Tegangan tanah awal $\left(\mathrm{kg} / \mathrm{m}^{2}\right) ;$ dan

$\sigma_{z f}=$ Tegangan tanah akhir, yaitu tegangan tanah awal+tegangan akibat beban luar $\left(\sigma_{z f}=\sigma_{z 0}+\Delta \sigma_{z}\right)\left(\mathrm{kg} / \mathrm{m}^{2}\right)$.

Sedangkan untuk kondisi konsolidasi berlebih, penurunan dapat dihitung dengan persamaan berikut:

$$
S c=\frac{C c}{1+e_{0}} H \log \left(\frac{\sigma^{!} z f}{\sigma^{!} z_{0}}\right)+\frac{C c}{1+e_{0}} H \log \left(\frac{\sigma^{!} z f}{\sigma^{!} z c}\right)
$$

Keterangan:

$$
\sigma_{z c}=\text { Preconsolidation Pressure } \quad\left(\mathrm{kg} / \mathrm{m}^{2}\right)
$$

Meyerhoff (1956) menyatakan bahwa penurunan izin yang terjadi pada lapisan tanah dasar akibat beban di atasnya adalah sebesar 2,54 cm (1"). Apabila penurunan lebih besar dari 2,54 cm (1") maka penurunan dianggap tidak aman. Sebaliknya, penurunan lebih kecil dari 2,54 cm (1") maka penurunan dianggap aman (Hardiyatmo, 1996); (D. Nasution et al., 2018)

\section{Hasil dan Pembahasan}

\subsection{Penurunan Pada Kondisi Eksisting Menggunakan Plaxis 2D}

Hasil perhitungan penurunan pada kondisi eksisting dengan menggunakan program Plaxis $2 D$, sesuai dengan parameter tanah seperti pada Tabel 2 serta menggunakan beban kendaraan yaitu sebesar $15 \mathrm{kN} / \mathrm{m}^{2}$, seperti diperlihatkan pada Gambar 4, 5, 6 dan 7. 


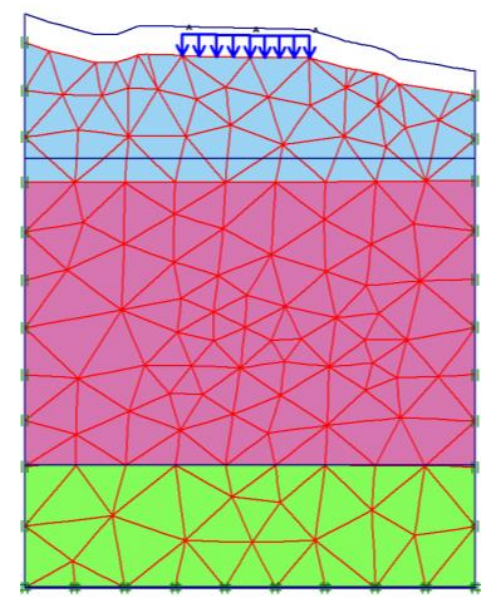

Jaringan Elemen Terdeformasi Perpindahan Total Ekstrim $163,58 * 10^{-3} \mathrm{~m}$

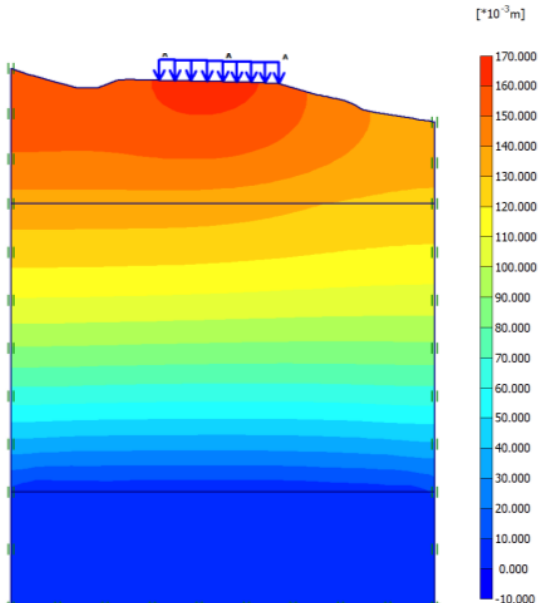

Perpindahan Total (Utot) Nilai Ekstrim Utot $163,58 * 10^{-3} \mathrm{~m}$

Keterangan :

= Tanah lapisan 1 (Pasir);

$=$ Tanah lapisan 2 (Pasir Berlempung); dan

$=$ Tanah lapisan 3 (Lempung).

Gambar 4 Jaring elemen terdeformasi (deformed mesh) kondisi eksisting

Gambar 4 menunjukan bahwa perhitungan konsolidasi pada kondisi eksiting menggunakan program Plaxis 2D didapatkan angka Jaring Elemen Terdeformasi sebesar $163,58 \mathrm{~m} \mathrm{x} 10^{-3}$ yaitu $16,358 \mathrm{~cm}$ dalam kondisi tidak aman (batas-batas toleransi $>2,54 \mathrm{~cm})$.

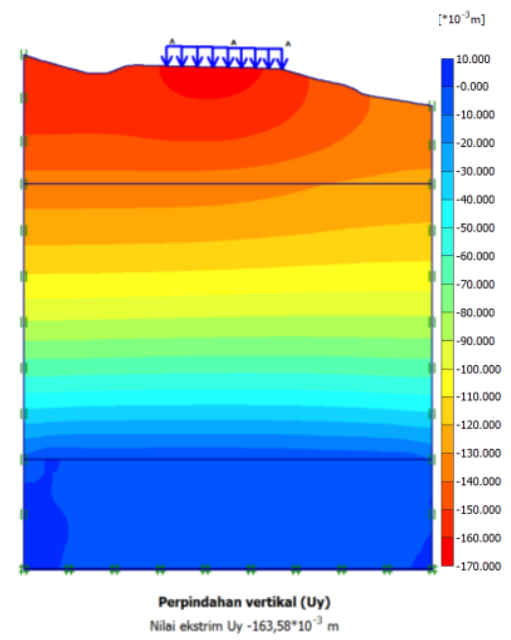

Gambar 5 Perpindahan vertikal (Uy) kondisi eksisting

Jaringan elemen terdeformasi terjadinya penurunan maksimum dengan jangka waktu yang tidak dapat ditentukan pada ruas jalan tersebut. Dengan demikian, maka diperlukan pencegahan terjadinya penurunan pada badan jalan.

Gambar 5 menunjukan bahwa perhitungan konsolidasi pada kondisi eksiting menggunakan program Plaxis $2 D$ didapatkan angka Perpindahan Vertikal (Uy) sebesar $163,58 \mathrm{~m} \mathrm{x} 10^{-3}$ yaitu $16,358 \mathrm{~cm}$. Perpindahan vertikal terjadinya 
penurunan secara vertikal yang akan menyebabkan badan mengalami penurunan maksimum dengan batas waktu yang tidak dapat ditentukan. Berdasarkan gambar 6 menunjukan bahwa pada lapisan 1 (Pasir) mengalami penurunan yang signifikan dan lapisan 2 (Pasir Berlempung) mengalami penurunan stabil serta pada lapisan 3 (Lempung) tidak terjadinya penurunan.

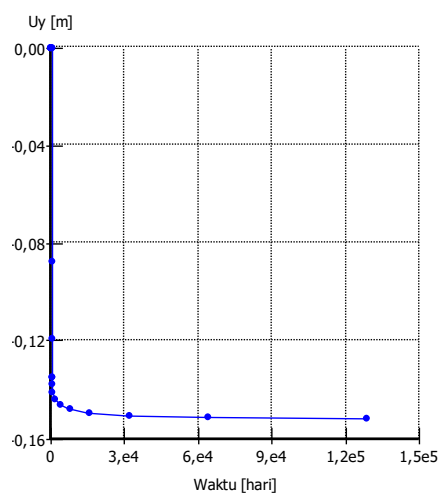

Gambar 6 Hubungan penurunan vertikal (Uy) dengan waktu (hari) kondisi eksisting

Tabel 4 Perhitungan penurunan pada kondisi eksisting

\begin{tabular}{ccc}
\hline Langkah & Waktu (Tahun) & Penurunan $(\mathbf{C m})$ \\
\hline 0 & 0,00 & 0,00 \\
\hline 1 & 0,00 & 0,00 \\
\hline 2 & 0,50 & 0,00 \\
\hline 3 & 1,00 & 0,00 \\
\hline 4 & 1,00 & 0,00 \\
\hline 5 & 1,50 & 0,00 \\
\hline 6 & 2,00 & 0,00 \\
\hline 7 & 2,00 & 0,00 \\
\hline 8 & 2,25 & $-8,74$ \\
\hline 9 & 2,75 & $-11,91$ \\
\hline 10 & 3,00 & $-13,51$ \\
\hline 11 & 3,00 & $-13,51$ \\
\hline 12 & 3,00 & $-13,76$ \\
\hline 13 & 3,00 & $-14,10$ \\
\hline 14 & 5,79 & $-14,40$ \\
\hline 15 & 11,36 & $-14,64$ \\
\hline
\end{tabular}

Gambar 7 dan Tabel 4 menunjukan bahwa perhitungan konsolidasi pada kondisi eksisting menggunakan program Plaxis $2 D$ didapatkan angka Penurunan yaitu sebesar -14,64 cm dalam jangka waktu Tv = 11,36 Tahun dengan kondisi Tidak Aman (batas-batas toleransi $>2,54 \mathrm{~cm}$ ).

\subsection{Perhitungan Penurunan Setelah Diperkuat Pondasi Cakar Ayam Modifikasi Menggunakan Plaxis 2D}

Hasil perhitungan penurunan setelah diperkuat pondasi Cakar Ayam Modifikasi (CAM) dengan menggunakan program Plaxis 2D. Adapun dimensi dan parameter input pondasi cakar Ayam Modifikasi (CAM) seperti yang 
diperlihatkan pada Gambar 4 dan Tabel 1 serta menggunakan beban kendaraan yaitu sebesar $15 \mathrm{kN} / \mathrm{m}^{2}$, seperti diperlihatkan pada Gambar 7, 8 dan 9 .

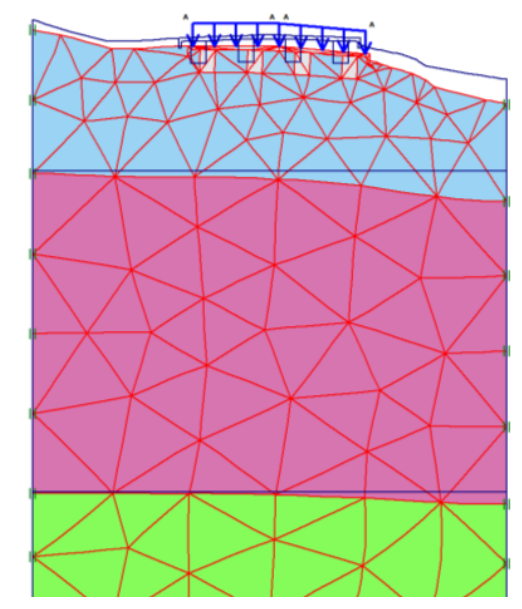

Jaringan Elemen Terdeformasi Perpindahan Total Ekstrim 3,27*10 $10^{-3} \mathrm{~m}$

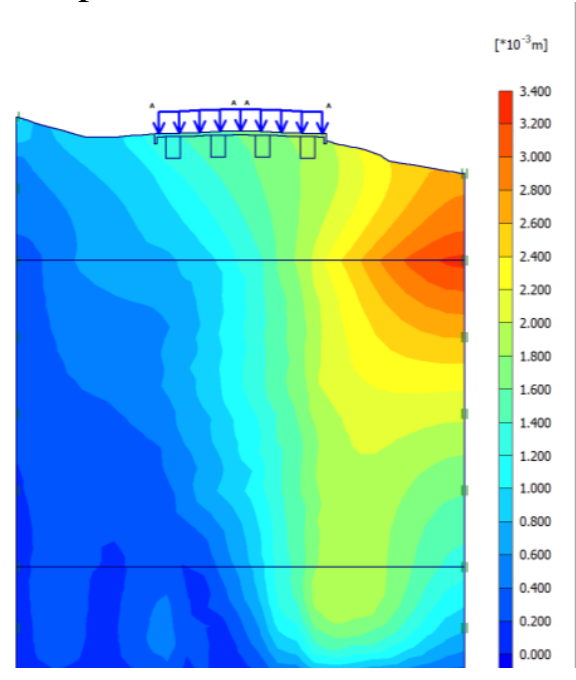

Perpindahan Total (Utot) Nilai Ekstrim Utot $3,27 * 10^{-3} \mathrm{~m}$

Gambar 7 Jaring elemen terdeformasi (deformed mesh)) setelah diperkuat pondasi cakar ayam modifikasi (CAM)

Gambar 7 menunjukan bahwa perhitungan konsolidasi Setelah Diperkuat Pondasi Cakar Ayam Modifikasi (CAM) menggunakan program Plaxis 2D didapatkan angka Jaring Elemen Terdeformasi sebesar 3,27 m x $10^{-3}$ yaitu 0,327 $\mathrm{cm}$ dalam kondisi aman (batas-batas toleransi $<2,54 \mathrm{~cm}$ ).

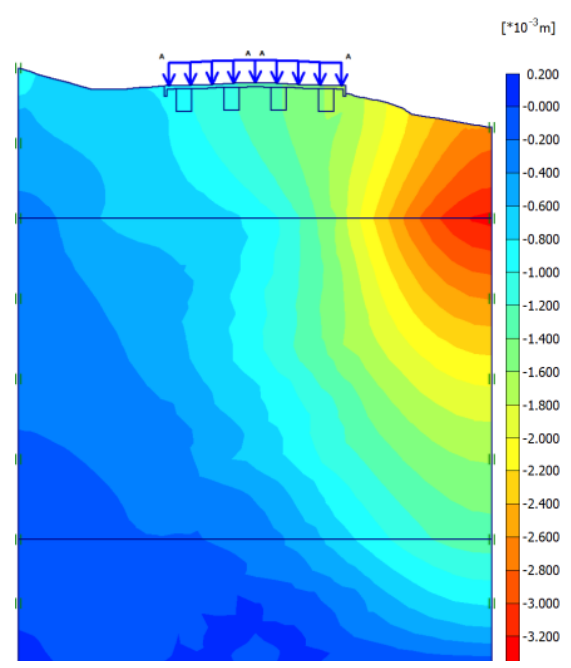

Perpindahan vertikal (Uy)

Nilai Ekstrim Uy $-3,27 * 10^{-3} \mathrm{~m}$

Gambar 8 Perpindahan vertikal (Uy) setelah diperkuat pondasi cakar ayam modifikasi (CAM)

Gambar 8 menunjukan bahwa perhitungan konsolidasi pada Setelah Diperkuat Pondasi Cakar Ayam Modifikasi (CAM) menggunakan program Plaxis 
$2 D$ didapatkan angka Perpindahan Vertikal (Uy) yaitu sebesar $-0,327 \mathrm{~cm}$. Perpindahan vertikal terjadinya penurunan secara vertikal yang akan menyebabkan badan mengalami penurunan maksimum dengan batas waktu yang tidak dapat ditentukan

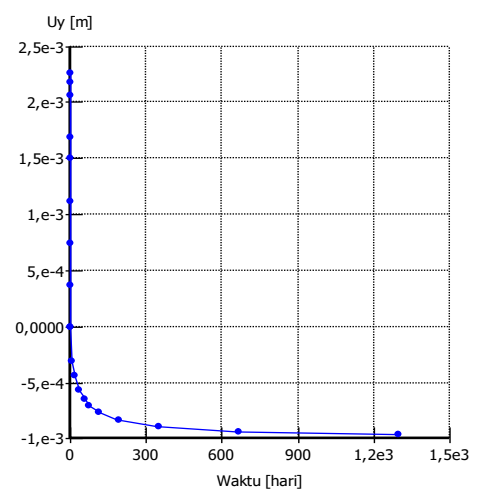

Gambar 9 Hubungan perpindahan vertikal (Uy) dengan waktu (hari) setelah diperkuat pondasi cakar ayam modifikasi (CAM)

Tabel 5 Perhitungan penurunan pada setelah diperkuat pondasi cakar ayam modifikasi (CAM)

\begin{tabular}{ccc}
\hline Langkah & Waktu (Tahun) & Penurunan $(\mathbf{C m})$ \\
\hline 0 & 0,00 & 0,00 \\
\hline 1 & 0,03 & $-0,03$ \\
\hline 2 & 0,05 & $-0,04$ \\
\hline 3 & 0,11 & $-0,06$ \\
\hline 4 & 0,16 & $-0,06$ \\
\hline 5 & 0,22 & $-0,07$ \\
\hline 6 & 0,33 & $-0,08$ \\
\hline 7 & 0,55 & $-0,08$ \\
\hline 8 & 0,98 & $-0,09$ \\
\hline 9 & 1,86 & $-0,09$ \\
\hline 10 & 3,60 & $-0,10$ \\
\hline
\end{tabular}

Gambar 9 dan Tabel 5 menunjukan bahwa perhitungan konsolidasi setelah diperkuat Pondasi Cakar Ayam Modifikasi (CAM) menggunakan program Plaxis 2D didapatkan angka Penurunan yaitu sebesar $-0,10 \mathrm{~cm}$ dalam jangka waktu $\mathrm{Tv}=$ 3,60 tahun dengan kondisi Aman (batas-batas toleransi $<2,54 \mathrm{~cm}$ ).

\subsection{Pembahasan}

Berdasarkan hasil analisis konsolidasi pada Ruas Jalan Subulussalam Lipat Kajang Km 605+400 menggunakan parameter input tanah seperti pada Tabel 2 dan beban kendaraan yaitu sebesar $15 \mathrm{kN} / \mathrm{m}^{2}$ dengan program Plaxis 2D pada kondisi eksiting, didapatkan angka penurunan yaitu lebih besar dari $2,54 \mathrm{~cm}$ (batas-batas toleransi) dengan jangka waktu diatas 11,36 tahun dalam kondisi badan jalan tidak aman. Hal ini dapat disebabkan oleh kondisi tanah pada lokasi tersebut atau dikarenakan pada lapisan tanah dasar terdapat kondisi tekanan air, sehingga dapat menyebabkan penurunan yang besar (diatas batas-batas toleransi). Dengan demikian, maka dilakukan perkuatan menggunakan Pondasi Cakar Ayam Modifikasi (CAM) dengan dimensi dan parameter input seperti yang diperlihatkan pada Gambar 4 dan Tabel 2. 
Hasil analisis konsolidasi setelah diperkuat Pondasi Cakar Ayam Modifikasi (CAM) pada Ruas Jalan Subulussalam - Lipat Kajang Km 605+400 beban kendaraan sebesar $15 \mathrm{kN} / \mathrm{m}^{2}$ dengan menggunakan program Plaxis 2D, didapatkan angka penurunan yaitu lebih kecil dari $2,54 \mathrm{~cm}$ dengan jangka waktu dibawah $\mathrm{Tv}=3,60$ tahun dengan kondisi badan jalan aman.

\section{Kesimpulan dan Saran}

\subsection{Kesimpulan}

Konsolidasi pada kondisi eksisting menggunakan program Plaxis 2D didapatkan angka penurunan yaitu lebih besar dari $2,5 \mathrm{~cm}$ (batas-batas toleransi) dengan jangka waktu di atas 11,36 tahun dengan kondisi badan jalan tidak aman. Setelah diperkuat Pondasi Cakar Ayam Modifikasi (CAM) menggunakan program Plaxis 2D didapatkan angka penurunan yaitu lebih kecil dari $2,5 \mathrm{~cm}$ dengan jangka waktu dibawah Tv 3,60 tahun dengan kondisi badan jalan aman.

\subsection{Saran}

Saran sebagai rekomendasi dari penelitian ini, disarankan pada penelitian selanjutnya untuk menganalisis aliran air dalam tanah yang mengakibatkan terjadinya penurunan dengan software SEEP/W. Kepada peneliti selanjutnya untuk mengubah perkuatan lereng dengan menggunakan vertical drain.

\section{Daftar Kepustakaan}

Bowles, J. E. (1986). Analisa dan Disain Pondasi (1st ed.). Penerbit Erlangga. Bowles, J. E. (1993). Sifat-Sifat Fisis dan Geoteknis Tanah. Penerbit Erlangga.

Broere, W. (2004). Plaxis Finite Element Code for Soil and Rock Analysis. Plaxis Bulletin.

D. Nasution, L., Munirwansyah, M., \& Saleh, S. M. (2018). Analisis Hkritis Terhadap Daya Dukung Tanah Dasar. Jurnal Arsip Rekayasa Sipil dan Perencanaan, 1(2), 39-46. https://doi.org/10.24815/jarsp.v1i2.10940

Hardiyatmo, H. C. (1996). Teknik Fondasi 1. Gramedia Pustaka Utama.

Hardiyatmo, H. C. (2010). Perancangan Sistem Cakar Ayam Modifikasi untuk Pekerasan Jalan Raya. Gadjah Mada University Press.

Hardiyatmo, H. C. (2017). Perancangan Perkerasan Jalan \& Penyelidikan Tanah (2nd ed.). Gadjah Mada University Press.

Punmia, DR. BC. (1981). Soil Mechanics and Foundations. Rajinder Kumar Jain.

Umum, D. P. (2009). Perencanaan dan Pelaksanaan Perkuatan Tanah dengan Geosintetik. Departemen Pekerjaan Umum.

Wirhadi, W., Munirwansyah, M., \& Saleh, S. M. (2018). Analisis Stabilitas Lereng Menggunakan Software Plaxis 8.6 Dengan Dinding Penahan Tanah (Retaining Wall) (Studi Kasus Ruas Jalan Nasional Banda Aceh-Medan Sta 83+135 Gunung Seulawah). Jurnal Arsip Rekayasa Sipil dan Perencanaan, 1(3), 76-82. https://doi.org/10.24815/jarsp.v1i1.11768 